\title{
Analgesic efficacy and safety of a caudal bupivacaine-fentanyl mixture in children
}

The analgesic efficacy and safety of a single caudal injection of a bupivacaine-fentanyl mixture was investigated in this prospective, controlled, triple-blinded study of 34 children, aged 1-11 yr and of ASA physical status I-II undergoing urological surgery. After induction of anaesthesia and before surgery, the children were randomly assigned to receive a caudal injection of $1.0 \mathrm{ml} \cdot \mathrm{kg}^{-1}$ bupivacaine $0.125 \%$ with epinephrine $1: 400,000$ and either fentanyl $1.0 \mu \mathrm{g} \cdot \mathrm{kg}^{-1}$ in $1.0 \mathrm{ml}$ of normal saline or 1.0 $\mathrm{ml}$ of normal saline. After completion of surgery, patients were assessed in the recovery room for six hours from the time of the caudal injection and for a further $18 \mathrm{hr}$ on the ward. While in the recovery room arterial oxygen saturation and respiratory rate were monitored continuously and recorded hourly together with end-tidal carbon dioxide, pain and sedation scores. Other complications were also recorded. While on the ward, pain and sedation scores, respiratory rate and side effects were recorded every two hours. Postoperative analgesia was provided by intravenous morphine. Analgesic requirements were recorded for the 24-hr study period. Pain and sedation scores did not differ between groups. Respiratory depression or hypoxia did not occur. The incidences of other side effects did not differ. There were no differences in the numbers of patients requiring morphine within eight hours, the time to first morphine administration or the total morphine requirements. We conclude that a single caudal injection of a bupivacaine-fentanyl mixture

\section{Key words}

ANALGESIA: postoperative;

ANALGESICS: opioids, fentanyl;

ANAESTHESIA: paediatric;

ANAESTHETIC TECHNIQUES: caudal;

ANAESTHETICS, LOCAL: bupivacaine.

From the Department of Anaesthesia, The Hospital for Sick Children, University of Toronto, Toronto Ontario, Canada M5G 1X8. Presented in part at the Annual Meeting of The American Society of Anesthesiologists, San Francisco, 1991.

Address correspondence to: Dr. B. Bissonnette, Department of Anaesthesia, The Hospital for Sick Children, 555 University Avenue, Toronto, Ontario, Canada, M5G 1 X8.

Accepted for publication 24th April, 1992. with epinephrine administered prior to surgery, while safe, offers no advantage over an injection of bupivacaine $0.125 \%$ with epinephrine for paediatric urological surgery.

Cette étude contrôlée prospective à triple inconnue évalue l'efficacité analgésique et la sécurité de l'injection caudale d'un mélange bupivacaïne-fentanyl effectuée chez des enfants de 1-11 ans, de classe ASA I et II, subissant une chirurgie urologique. Après l'induction de l'anesthésie et immédiatement avant la chirurgie, les enfants on été assignés au hasard a recevoir par injection caudale simple $1,0 \mu \mathrm{g} \cdot \mathrm{kg}^{-1}$ de bupivacaïne 0,125\% adrénalinée à 1:400,000 associée d̀ du fentanyl 1,0 $\mathrm{\mu g}$ dans $1,0 \mathrm{ml}$ de soluté physiologique ou à 1,0 ml de soluté physiologique. Après la chirurgie, les patients ont été surveillés à la salle de réveil pendant les six heures qui ont suivi l'injection, et à l'étage pour les dix-huit heures subséquentes. A la salle de réveil, la saturation oxyhémoglobininée et la fréquence ventilatoire ont été monitorés continuellement et enregistrées à toutes les heures de même que l'anhydride carbonique en fin de d'expiration, le niveau de perception douloureuse et de sédation sur des échelles appropriées. On a aussi noté les complications. A l'étage, les échelles d'évaluation de la douleur et de la sédation on été enregistrées à toutes les deux heures, de même que la fréquence ventilatoire et les effets secondaires. La morphine intraveineuse a assuré l'analgésie post-opératoire. Le besoin d'analgésiques a été enregistré pendant la périoded'étude de 24 heures. Les degrés de douleur et de sédation ont été identiques dans les groupes. Il n'y a pas eu de dépression respiratoire, ni d'hypoxie. L'incidence des autres effets secondaires n'a pas différé. Le nombre de patient pour lesquels la morphine a été requise pendant les huit premières heures, le délai requis avant la première injection et la dose totale ont été les mêmes. Nous en concluons que l'injection caudale simple d'un mélange de bupivacaïne-fentanyl avec épinéphrine administrée avant la chirurgie, tout en étant sans danger, n'offre pas plus d'avantages que l'injection de bupivacaïne $0,125 \%$ avec épinéphrine dans un contexte de chirurgie urologique en pédiatrie.

Caudal injections of bupivacaine may provide up to eight hours of postoperative analgesia in children. ${ }^{1}$ The addition of morphine to caudal bupivacaine has been found to 
improve both the quality and the duration of analgesia for children undergoing orchidopexy. ${ }^{2}$ However, respiratory depression has followed a caudal injection of morphine in a child. ${ }^{3}$ Fentanyl has been suggested as the opioid least likely to cause respiratory depression when given extradurally, because of its high lipid solubility. ${ }^{4}$ Studies in adults report improved and/or prolonged analgesia following the addition of fentanyl to lumbar extradural bupivacaine for lower abdominal procedures, ${ }^{5}$ Caesarean section $^{6}$ and pain relief in labour. ${ }^{7}$ In a small uncontrolled study of children undergoing lower abdominal surgery, the addition of fentanyl to a single caudal injection of bupivacaine provided analgesia for more than $24 \mathrm{hr}$ without effect on respiration. ${ }^{8}$ However, the effects of caudal mixtures of fentanyl and bupivacaine in children have not been assessed in a controlled study. We compared the analgesic efficacy and safety of a caudal injection of a bupivacaine-fentanyl mixture with those of bupivacaine alone in children undergoing urological procedures.

\section{Methods}

After Human Subject Review Committee approval of this controlled triple-blind study, written informed consent was obtained from the parents of 34 children, aged 1-11 yr and of ASA physical status I or II, scheduled for urological surgery expected to take less than three hours. Children with cardiovascular, respiratory or hepatic impairment were excluded. The children were fasted and unpremedicated. With the usual monitoring in place, anaesthesia was induced with thiopentone $5.0 \mathrm{mg} \cdot \mathrm{kg}^{-1}$ with atropine $0.02 \mathrm{mg} \cdot \mathrm{kg}^{-1}$. Tracheal intubation was facilitated by succinylcholine $1.5 \mathrm{mg} \cdot \mathrm{kg}^{-1}$ followed by intermittent positive pressure ventilation with halothane $0.5-1.5 \%$ and $70 \%$ nitrous oxide in oxygen. Pancuronium $0.10 \mathrm{mg} \cdot \mathrm{kg}^{-1}$ was given for further neuromuscular relaxation. After induction of anaesthesia and before surgery, the patients were randomly assigned to receive a caudal injection of: $1.0 \mathrm{ml} \cdot \mathrm{kg}^{-1}$ bupivacaine $0.125 \%$ with epinephrine $1: 400,000$ plus $1.0 \mathrm{ml}$ of either fentanyl 1.0 $\mu \mathrm{g} \cdot \mathrm{kg}^{-1}$ (group BF) or sterile saline (group B). At the end of surgery, neuromuscular relaxation was reversed with neostigmine $0.05 \mathrm{mg} \cdot \mathrm{kg}^{-1}$ and atropine $0.02 \mathrm{mg} \cdot \mathrm{kg}^{-1}$. All patients received oxygen $4 \mathrm{~L} \cdot \mathrm{min}^{-1}$ by facemask in the recovery room. Intravenous morphine $0.05-0.1 \mathrm{mg} \cdot \mathrm{kg}^{-1}$ was available for pain.

Patients were assessed in the recovery room for six hours from the time of the caudal injection, and for a further $18 \mathrm{hr}$ on the ward. While in the recovery room arterial oxygen saturation $\left(\mathrm{SpO}_{2}\right)$ and respiratory rate $(\mathrm{RR})$ were monitored continuously and recorded hourly together with end-tidal carbon dioxide $\left(\mathrm{PETCO}_{2}\right),{ }^{9}$ pain and sedation scores, and the presence of vomiting, shivering,
TABLE I Demographic data and duration of surgery for patients undergoing urologic surgery

\begin{tabular}{lll}
\hline & \multicolumn{2}{l}{ Group } \\
\cline { 2 - 3 } & Bupivacaine & Bupivacaine-fentanyl \\
\hline Number of patients & 17 & 17 \\
Age $(\mathrm{yr})^{*}$ & $4.6 \pm 3.8$ & $5.3 \pm 3.3$ \\
Weight $(\mathrm{kg}) *$ & $18.6 \pm 8.0$ & $20.0 \pm 7.8$ \\
Sex $(\mathrm{M} / \mathrm{F})$ & $8 / 9$ & $7 / 10$ \\
Duration of procedure $(\mathrm{hr})^{*}$ & $2.1 \pm 0.5$ & $2.2 \pm 0.9$ \\
\hline
\end{tabular}

${ }^{*}$ Mean \pm SD

pruritus or other complications. While on the ward, pain and sedation scores, RR and the presence of side effects were recorded every two hours. Pain was assessed using the Objective Pain-Discomfort Scale (OPS). ${ }^{10}$ Sedation was measured using a 4-point scale where $1=$ awake and 4 = unrousable. Respiratory depression was defined as a $\mathrm{PETCO}_{2}$ of greater than $50 \mathrm{mmHg}$ or a respiratory rate of less than 10 breaths $\cdot \min ^{-1}$. Hypoxia was defined as a $\mathrm{SpO}_{2}$ of less than $90 \%$. Analgesic requirements were recorded for the $24 \mathrm{hr}$ study period and analyzed as follows: the number of patients requiring morphine within eight hours, the time to first morphine administration and the total morphine requirements.

\section{Statistics}

A sample size of 60 was determined by power analysis assuming $\alpha=0.05, \beta=0.2$, and a difference of $30 \%$ between the groups in the number requiring morphine by eight hours ( $70 \%$ in group BF and $100 \%$ in group B). All parametric data are reported as mean \pm SD. Statistical significance $(P<0.05)$ was determined using the unpaired $t$ test for age, weight, duration of surgery, time to first dose of morphine and total morphine requirements; chi-square analysis for sex, the number of patients requiring morphine by eight hours and the incidences of side effects; and Mann-Whitney $U$ test for pain and sedation scores.

\section{Results}

The groups were of similar sample size, age, weight, sex and duration of surgery (Table I). Twelve patients in each group had undergone ureteral reimplantation and the remainder had undergone urethroplasty. There were no differences in pain and sedation scores between groups at any time. The incidence of side effects did not differ between groups (Table II) and no side effect required treatment. There was no respiratory depression and $\mathrm{SpO}_{2}$ did not decrease below $96 \%$ in any patient. The number of patients requiring morphine within eight hours (Figure 1), the time to first morphine administration (Figure 2) and the total dose of morphine per $24 \mathrm{hr}$ (Figure 3) did not differ 
TABLE II Side effects in patients during 24 hours from caudal injection

\begin{tabular}{lll}
\hline & Group \\
\cline { 2 - 3 } & Bupivacaine & Bupivacaine-fentanyl \\
\hline Number of patients & 17 & 17 \\
Respiratory depression & 0 & 0 \\
Vomiting* & $7(41)$ & $10(59)$ \\
Shivering* & $2(12)$ & $3(18)$ \\
Pruritus* & $2(12)$ & $2(12)$ \\
\hline
\end{tabular}

*Number (\%).

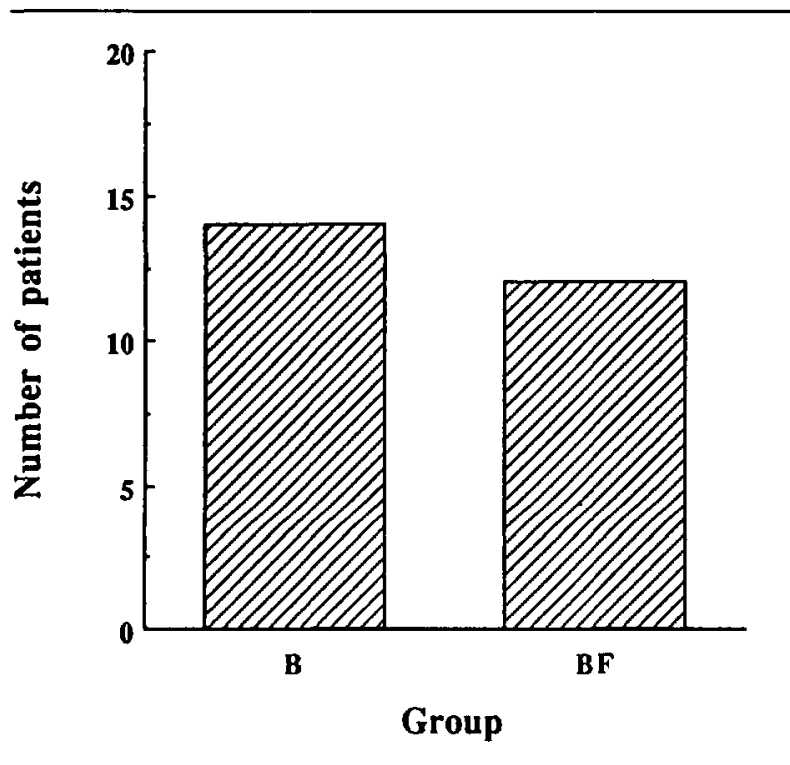

FIGURE 1 Number of patients requiring morphine within eight hours of caudal injection of bupivacaine (B) or bupivacaine-fentanyl (BF).

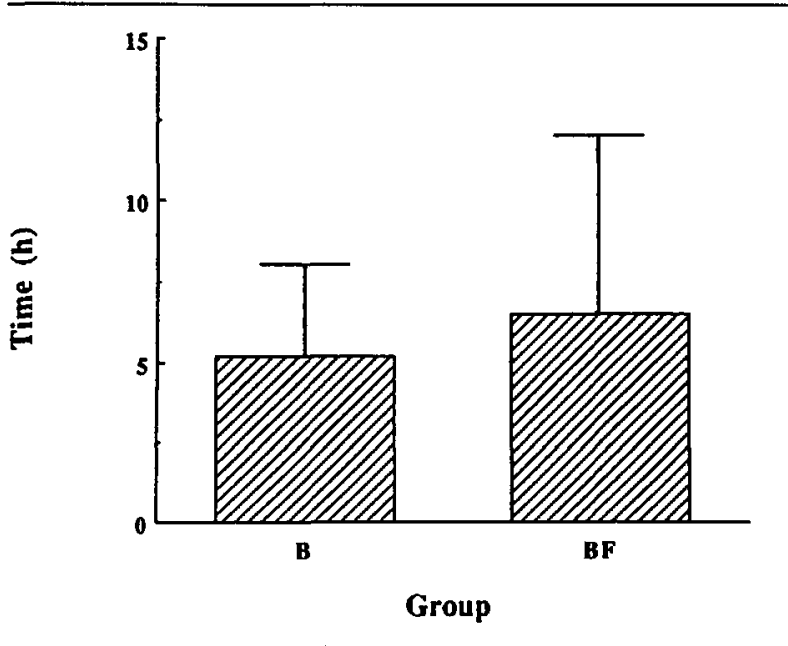

FIGURE 2 Time to first dose of morphine after caudal injection of bupivacaine (B) or bupivacaine-fentanyl (BF).

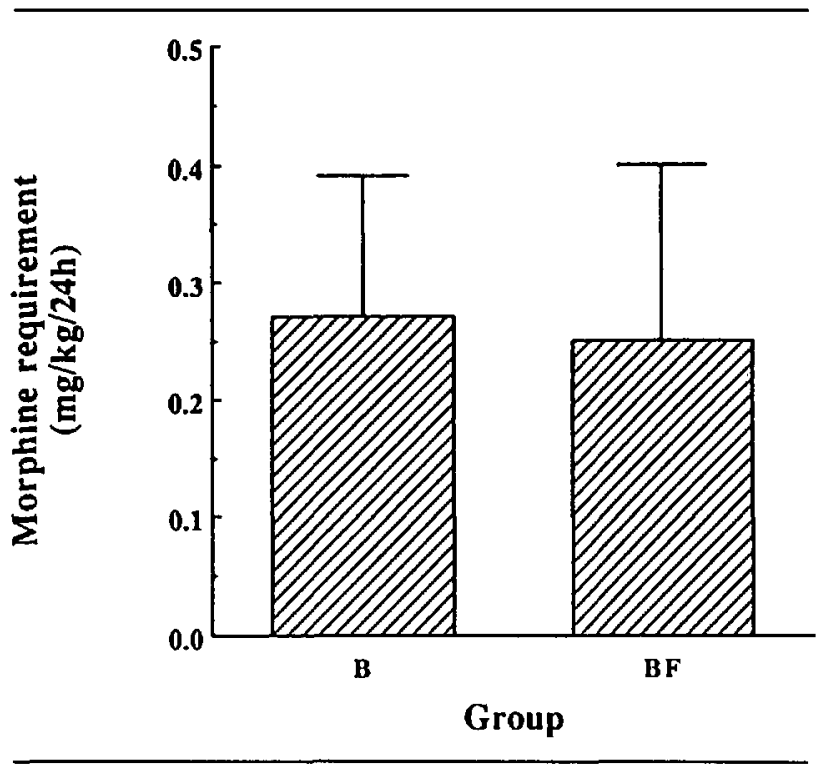

FIGURE 3 Total morphine requirements after caudal injection of bupivacaine (B) or bupivacaine-fentanyl (BF).

between groups. There were no complications as a result of this study. The study was terminated after 34 patients.

\section{Discussion}

When administered as a single caudal injection, a bupivacaine-fentanyl mixture neither improved nor prolonged postoperative analgesia compared with bupivacaine alone in this investigation. No respiratory depression occurred and other side effects were minor and did not require treatment. The data was analyzed after 34 patients for preliminary presentation. Power analysis revealed that over 300 patients would be required in each group for the observed difference in morphine requirements to reach statistical significance. Our analysis coincided with the publication of a controlled study in which the addition of fentanyl $1.0 \mu \mathrm{g} \cdot \mathrm{kg}^{-1}$ to caudally-administered lidocaine $2 \%$, while safe, conveyed no benefit to children undergoing circumcision. ${ }^{11}$ These factors, together with the demands on the recovery room and on the ward, led us not to resume the study. Although our investigation is incomplete, we felt it important to report our data.

Our findings contrast with those of an uncontrolled study in which fentanyl $1.0 \mu \mathrm{g} \cdot \mathrm{kg}^{-1}$ was added to 1.0 $\mathrm{ml} \cdot \mathrm{kg}^{-1}$ of caudally administered bupivacaine $0.25 \%$ in seven children undergoing abdominal surgery, in which over 24 hours' analgesia was reported. ${ }^{8}$ However, in that study, analgesia was defined only by pain scores and analgesic requirements were not mentioned. Our findings are consistent with those of a subsequent study of caudal fentanyl-lidocaine mixture. ${ }^{11}$

Although the addition of fentanyl to lumbar extradural bupivacaine has been beneficial in adults, ${ }^{5-7}$ this finding is 
not consistent. In adults undergoing lower abdominal surgery, extradural fentanyl prolonged the analgesia provided by bupivacaine $0.5 \%$ when $200 \mu \mathrm{g}$ but not when $100 \mu \mathrm{g}$ or $50 \mu \mathrm{g}$ was given. ${ }^{5}$ There was one case of mild respiratory depression in a patient who received $200 \mu \mathrm{g}$, but this was mild and did not require treatment. In a double-blind study of fentanyl $100 \mu \mathrm{g}$ added to lumbar extradural bupivacaine for Caesarean section, the quality of analgesia was improved. ${ }^{6}$ However, the onset and duration of analgesia did not change, and in a similar study, neither the quality nor the duration of analgesia was affected. ${ }^{12}$ Fentanyl did not improve analgesia for women in labour when $50 \mu \mathrm{g}$ or $100 \mu \mathrm{g}$ was added to bupivacaine $0.25 \% .{ }^{13} \mathrm{~A}$ dose-response study would be required to investigate whether caudal fentanyl at higher doses improved or increased the risk of respiratory depression in children.

In summary, we conclude that for paediatric urological surgery, a single caudal injection of $1.0 \mathrm{ml}$ fentanyl 1.0 $\mu \mathrm{g} \cdot \mathrm{kg}^{-1}$ mixed with $1.0 \mathrm{ml} \cdot \mathrm{kg}^{-1}$ bupivacaine $0.125 \%$ plus epinephrine offers no advantage over $1.0 \mathrm{ml} \cdot \mathrm{kg}^{-1}$ bupivacaine $0.125 \%$ plus epinephrine alone.

\section{Acknowledgements}

The authors wish to thank the nursing staff of the recovery room, and the division of urologic surgery. We are grateful to Dr. J. Lerman for his advice. We thank Dr. J.E.S. Relton for his assistance in the preparation of this manuscript.

\section{References}

1 Lloyd-Thomas AR. Pain management in paediatric patients. Br J Anaesth 1990; 64: 85-104.

2 Wolf AR, Hughes D, Wade A, Mather SJ, Prys-Roberts $C$. Postoperative analgesia after paediatric orchidopexy: evaluation of a bupivacaine-morphine mixture. $\mathrm{Br} \mathrm{J}$ Anaesth 1990; 64: 430-5.

3 Krane EJ. Delayed respiratory depression in a child after caudal epidural morphine. Anesth Analg 1988; 67: 79-82.

4 Morgan $M$. The rational use of intrathecal and extradural opioids. Br J Anaesth 1989; 63: 165-88.

5 Rucci FS, Cardamone M, Migliori P. Fentanyl and bupivacaine mixtures for extradural blockade. $\mathrm{Br} \mathrm{J}$ Anaesth 1985; 57: 275-84.

6 Paech MJ, Westmore MD. Speirs HM. A double-blind comparison of epidural bupivacaine and bupivacainefentanyl for Caesarean section. Anaesth Intensive Care 1990; 18: 22-30.

7 Celleno D, Capogna G. Epidural fentanyl plus bupivacaine 0.125 per cent for labour: analgesic effects. Can J Anaesth 1988; 35: 375-8.

8 Moine P, Ecoffey C. Bupivacaine caudal block with fentanyl in children. Anesthesiology 1989; 71: A1017.
9 Campbell FA, Swartz J, Bissonnette B, Mcleod ME. Noninvasive monitoring of end-tidal $\mathrm{CO}_{2}$ in infants and children in the recovery room. Can J Anaesth 1991; 38: A138.

10 Hanallah RS, Broadman LM, Belman AB, Abramowitz $M D$, Epstein BS. Comparison of caudal and ilioinguinal/iliohypogastric nerve blocks for control of post-orchidopexy pain in pediatric ambulatory sugery. Anesthesiology 1987; 66: 832-4.

11 Jones RDM, Gunawardene Wms, Yeung CK. A comparison of lignocaine $2 \%$ with adrenaline $1: 200,000$ and lignocaine $2 \%$ with adrenaline 1:200,000 plus fentanyl as agents for caudal anaesthesia undergoing circumcision. Anaesth Intensive Care 1990; 18: 194-9. 